\title{
New Technique for Imaging Geologic Materials via Integrated Correlative Light and Electron Microscopy (iCLEM)
}

\author{
Paul C. Hackley ${ }^{1}$, Brett J. Valentine ${ }^{1}$, Daan van Oosten Slingeland ${ }^{2}$, Lennard Voortman ${ }^{2}$, and
} Javin Hatcherian $^{1}$

1. U.S. Geological Survey, Reston VA 20192, United States

2. Delmic BV, The Netherlands

We describe an integrated correlative light and electron microscopy (iCLEM) approach for sequential imaging of geologic materials (shale and mudstone) utilizing both microscope techniques without sample transfer. By avoiding sample transfer this technique identifies low maturity organic matter at micron-scale $(1,000 \mathrm{x}$ magnifications) and can be followed by characterization at nano-scale (25,000-100,000x magnifications), potentially benefiting studies of organic nano-porosity, which is thought to control hydrocarbon storage and migration in shale petroleum systems [1]. Organic matter in shale, e.g., kerogen vs. solid bitumen, is easily identified by standard optical microscopy techniques such as epifluorescence and incident white light microscopy under oil immersion [2]. However, optical microscopy is diffraction-limited to resolutions of about 1 micron in practice, prohibiting nano-scale observation. Scanning electron microscopy (SEM) allows resolution of features $<10 \mathrm{~nm}$, thereby enabling study of organic nano-porosity [3]. Although organic matter is easily identified in SEM by its characteristic low backscatter electron (BSE) intensity, SEM is poorly suited to identify individual organic matter types. Therefore, correlative microscopy [4] or iCLEM studies are necessary to identify organic matter types in which organic nano-porosity develops and the thermal regime of formation.

Standard uncovered rock thin section preparations were intentionally wedged (polished to a vanishing edge on one side) followed by further thinning via broad ion beam (BIB) milling at the vanishing edge, ultimately creating a potential examination area of about 5x2 mm. For iCLEM we used the Delmic SECOM platform installed on an FEI Verios $460 \mathrm{~L}$ scanning electron microscope with sequential top-down SEM using both backscatter and/or secondary electron detectors, and bottom-up fluorescence imaging with the sample positioned in the middle.

The utility of iCLEM for geologic materials is illustrated in the images of Fig. 1 where a wide field of view in Fig. 1A includes an SEM region of interest (ROI, light gray square, upper left), whereas Fig. 1B shows an enlarged view of the area marked by the red rectangle in Fig. $1 \mathrm{~A}$ at a 30:70 fluorescence to SEM display ratio. Two types of organic matter are visible in Fig. 1B: nonfluorescent solid bitumen adjacent to strongly fluorescent amorphous organic matter. However, these organic matter types are indistinguishable in the 100\% SEM image of Fig 1C, due to the lack of grayscale contrast. Fig. 1D shows an enlargement of the ROI marked by the red rectangle in Fig. 1C, where combined SEM and fluorescence images resolve sub-micron carbonate and the two organic matter types are differentiated on the basis of fluorescence. The pinkish-red in the carbonate shown in Fig. 1A-B and 1D is from cathodoluminescence, which allows diagenetic observations which may not be as apparent with a single microscope application. Cathodoluminescence was present within concretions-microbialites, but subdued in adjacent organic-rich layers, and present in carbonate mineral cores, but absent in euhedral crystal overgrowths which terminated against sedimentary organic matter including both solid bitumen 
and amorphous material. Limitations of the technique as applied to shale organic nano-porosity include quenching of fluorescence at thermal maturities higher than about $1.0 \%$ vitrinite reflectance $\left(\mathrm{VR}_{0}\right)$, thereby relegating application as described to samples of peak oil window and lower thermal maturity. However, preparation as thin foils via focused ion beam milling may allow iCLEM via white light microscopy on SECOM or inverted SEM thru a thin film of silicon nitride [5] which potentially could extend the application to overmature conditions.

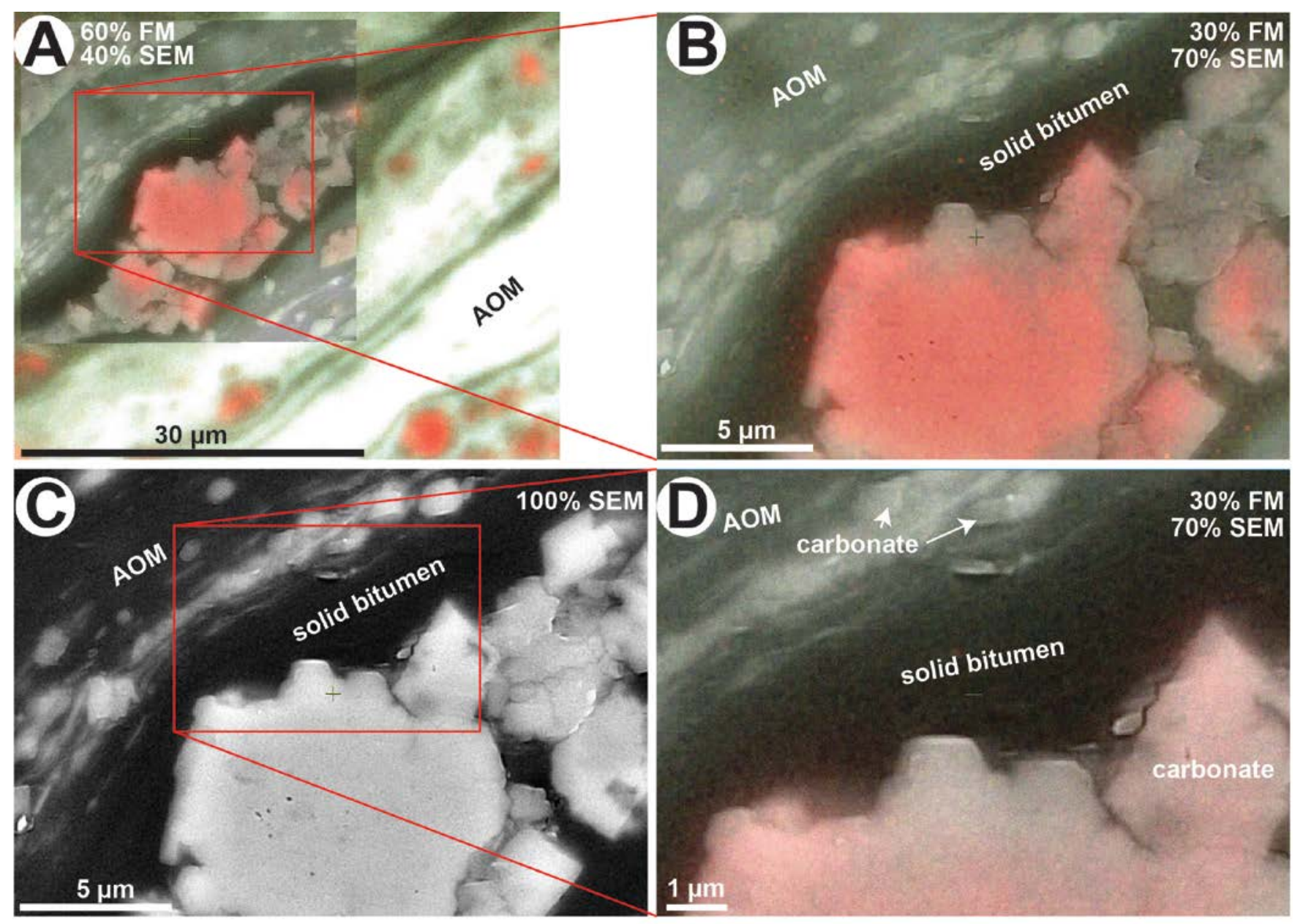

Figure 1. iCLEM images from Green River Mahogany Zone sample [6]. A. 60\% fluorescence microscopy (FM), 40\% SEM overlay. B. 30:70 FM to SEM view of zoom-in region in A. C. Same field as B with $100 \%$ SEM view. D. Zoom-in to region of interest shown as red rectangle in C with 30:70 FM to SEM view. False color fluorescence with 474 and $554 \mathrm{~nm}$ excitation. Cathodoluminescence shown in pinkish-red. SEM imaging at $20 \mathrm{kV}$. AOM = amorphous organic matter.

[1] Löhr, S.C., et al., Organic Geochemistry 87 (2015), p. 119-132.

[2] Hackley, P.C. and B.J. Cardott, International Journal of Coal Geology 163 (2016), p. 8-51.

[3] Loucks, R.G., et al., Journal of Sedimentary Research 79 (2009), p. 848-861.

[4] Fishman, N.S., et al., International Journal of Coal Geology 103 (2012), p. 32-50.

[5] Nishiyama, H., et al., Journal of Structural Biology 169 (2010), p. 438-449.

[6] Hackley, P.C., et al., Marine and Petroleum Geology 59 (2015), p. 22-34. 